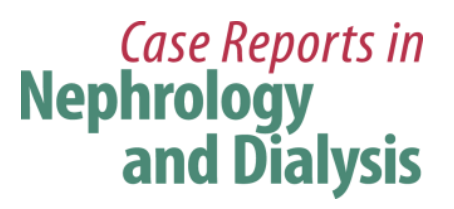

Case Rep Nephrol Dial 2017;7:108-111

DOI: $10.1159 / 000477664$

Published onlıne: July 19, 2017

\title{
Tolvaptan for the Treatment of Enlarged Polycystic Liver Disease
}

\author{
Hiroki Mizuno $^{a}$ Junichi Hoshino ${ }^{a}$ Tatsuya Suwabe $^{a}$ Keiichi Sumida ${ }^{a}$ \\ Akinari Sekine $^{a}$ Yoichi Oshima $^{a}$ Masahiko Oguro ${ }^{a}$ Kyohei Kunizawa ${ }^{a}$

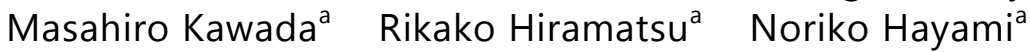 \\ Eiko Hasegawa $^{a}$ Masayuki Yamanouchi ${ }^{a}$ Naoki Sawa ${ }^{a}$ \\ Kenmei Takaichi $i^{a, b} \quad$ Yoshifumi Ubara ${ }^{a, b}$ \\ ${ }^{a}$ Nephrology Center, Toranomon Hospital Kajigaya, Kawasaki, Japan; ${ }^{b}$ Okinaka Memorial \\ Institute for Medical Research, Toranomon Hospital Kajigaya, Kawasaki, Japan
}

\section{Keywords}

Tolvaptan · Autosomal dominant polycystic kidney disease · Polycystic liver disease

\begin{abstract}
A 44-year-old Japanese woman with autosomal dominant polycystic kidney disease was admitted to our hospital for evaluation of abdominal distension. Her eGFR was $53.7 \mathrm{~mL} / \mathrm{min} /$ $1.73 \mathrm{~m}^{2}$. Total kidney volume was $2,614 \mathrm{~mL}$. Tolvaptan ( $60 \mathrm{mg} /$ day) was started to treat renal involvement. The patient's abdominal fullness began to improve and liver volume, indicating advanced polycystic liver disease (PLD), decreased from $9,750 \mathrm{~mL}$ to $8,345 \mathrm{~mL}$ after 17 months of tolvaptan treatment, though there was no significant change in kidney volume. This case indicates that tolvaptan may be a therapeutic option for hepatomegaly in patients with symptomatic PLD.

\section{Introduction}

Polycystic liver disease (PLD) is a serious complication of autosomal dominant polycystic kidney disease (ADPKD) $[1,2]$. Patients with massive hepatomegaly often require surgical treatment or percutaneous transcatheter hepatic artery embolization $[2,3]$, since there are 


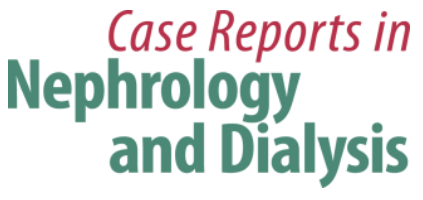

Case Rep Nephrol Dial 2017;7:108-111

DOI: 10.1159/000477664

(C) 2017 The Author(s). Published by S. Karger AG, Basel www.karger.com/cnd

Mizuno et al.: Tolvaptan for the Treatment of Enlarged Polycystic Liver Disease

few medical options with proven efficacy for PLD. Candidate drugs for treating PLD include somatostatin analogues, such as lanreotide and octreotide, which may inhibit the growth of liver cysts [4,5]. Mammalian target of rapamycin inhibitors, including everolimus and sirolimus, have also been tried as a second option [6]. However, the efficacy of these agents is relatively limited, and long-term safety is unclear. Iijima et al. [7] reported that ursodeoxycholic acid was safe and effective in suppressing the increase in liver volume and reducing serum levels of biliary enzymes. Torres et al. [8] showed that tolvaptan slowed the increase rate of total kidney volume and the decline of renal function over a 3-year period in ADPKD patients compared with placebo, but they did not report improvement of liver volume. We encountered a patient in whom liver volume decreased after the administration of tolvaptan.

\section{Case Report}

A 44-year-old Japanese woman was admitted to our hospital for evaluation of abdominal distension. She was $164 \mathrm{~cm}$ tall and weighed $74 \mathrm{~kg}$, with a blood pressure of 143/93 $\mathrm{mm}$ Hg. Laboratory tests revealed that her serum creatinine (Cre) value was $0.91 \mathrm{mg} / \mathrm{dL}$, the estimated glomerular filtration rate (eGFR) was $53.7 \mathrm{~mL} / \mathrm{min} / 1.73 \mathrm{~m}^{2}$, and her albumin level was $3.6 \mathrm{~g} / \mathrm{dL}$. In addition, the total bilirubin level was $0.7 \mathrm{mg} / \mathrm{dL}$, aspartate aminotransferase was 23 IU/L (normal range: 13-33), alanine aminotransferase was 15 IU/L (normal range: 8-42), lactate dehydrogenase was 173 IU/L (normal range: 103-190), alkaline phosphatase was $268 \mathrm{IU} / \mathrm{L}$ (normal range: 117-350), $\gamma$-glutamyl transpeptidase was $74 \mathrm{IU} / \mathrm{L}$ (normal range: 9-109), and C-reactive protein was $0.8 \mathrm{mg} / \mathrm{dL}$. Urinary protein excretion was $0.1 \mathrm{~g} /$ day, and the urine sediment contained 1-4 erythrocytes per high-power field. Magnetic resonance imaging and computed tomography showed bilateral enlarged polycystic kidneys and a massive polycystic liver (Fig. 1). ADPKD was diagnosed, since her mother had this disease. Liver volume was calculated to be $10,173 \mathrm{~mL}$, indicating advanced PLD, while the total kidney volume was calculated as $2,614 \mathrm{~mL}$ by a previously reported method [7].

First, 3 large cysts were treated by aspiration and sclerotherapy using minocycline hydrochloride according to a reported method [7]. Her abdominal fullness improved immediately after $1,750 \mathrm{~mL}$ of cyst fluid was removed, but the improvement was only temporary. Liver volume increased to 9,750 $\mathrm{mL}$ again after 6 months, along with the exacerbation of abdominal symptoms. Tolvaptan therapy was started at a dose of $60 \mathrm{mg}$ daily to treat renal involvement (Cre of $0.89 \mathrm{mg} / \mathrm{dL}$ and eGFR of $54.6 \mathrm{~mL} / \mathrm{min} / 1.73 \mathrm{~m}^{2}$ ). After 1 month of tolvaptan therapy, abdominal fullness showed improvement and liver volume decreased to $9,219 \mathrm{~mL}$, while it decreased further to 8,963 mL after 12 months of treatment and to 8,345 $\mathrm{mL}$ after 17 months. Total kidney volume was $2,714 \mathrm{~mL}$ at the start of tolvaptan therapy, while it was 2,640 mL after 1 month and 2,832 mL after 17 months. There was no significant change in kidney volume during the 17-month treatment period, and renal function was also unchanged (Cre of $0.92 \mathrm{mg} / \mathrm{dL}$ and eGFR of $52.3 \mathrm{~mL} / \mathrm{min} / 1.73 \mathrm{~m}^{2}$ ).

\section{Discussion}

Somatostatin analogues have been tried as medical therapy for PLD [4, 5]. In 2009, van Keimpemaet al. [4] reported that treatment with the somatostatin analogue lanreotide reduced the mean liver volume from 4,606 mL to 4,471 mL. Also, Hogan et al. [5] reported in 2010 that octreotide, a long-acting somatostatin analogue, decreased the liver volume from 
5,908 $\mathrm{mL}$ to 5,557 $\mathrm{mL}$. Treatment with mammalian target of rapamycin inhibitors has also been attempted. According to Qian et al. [6], treatment with sirolimus for an average of 19.4 months achieved an $11.9 \%$ reduction of liver volume in ADPKD patients who had undergone kidney transplantation.

The improvement in liver volume obtained with tolvaptan in our patient may possibly be explained by a study of Mancinelli et al. [9], who reported that arginine vasopressin modulates cholangiocyte proliferation in rat and mouse models. In ADPKD, epithelial cells lining cysts in the kidneys and the liver are persistently stimulated to proliferate and secrete fluid, and such stimulation may be enhanced by increased circulating levels of arginine vasopressin in patients with polycystic kidney disease and PLD. It has been reported that V2 receptor modulators, such as tolvaptan, can suppress proliferation of the biliary epithelium in PLD [9].

\section{Conclusion}

The response of our patient to tolvaptan (the reduction in liver volume and improvement of abdominal symptoms) suggests that this drug may be a therapeutic option for hepatomegaly in patients with symptomatic PLD.

\section{Acknowledgment}

This study was funded by the Okinaka Memorial Institute for Medical Research.

\section{Statement of Ethics}

This study was approved by Toranomon Hospital institutional review board and the patients gave written informed consent.

\section{Disclosure Statement}

All authors declare that they have no competing financial or other conflicts of interests.

\section{References}

Chandok N: Polycystic liver disease: a clinical review. Ann Hepatol 2012;11:819-826.

Ogawa K, Fukunaga K, Takeuchi T, Kawagishi N, Ubara Y, Kudo M, Ohkohchi N: Current treatment status of polycystic liver disease in Japan. Hepatol Res 2014;44:1110-1118.

-3 Takei R, Ubara Y, Hoshino J, Higa Y, Suwabe T, Sogawa Y, Nomura K, Nakanishi S, Sawa N, Katori H, Takemoto F, Hara S, Takaichi K: Percutaneous transcatheter hepatic artery embolization for liver cysts in autosomal dominant polycystic kidney disease. Am J Kidney Dis 2007;49:744-752.

-4 van Keimpema L, Nevens F, Vanslembrouck R, van Oijen MG, Hoffmann AL, Dekker HM, de Man RA, Drenth JP: Lanreotide reduces the volume of polycystic liver: a randomized, double-blind, placebocontrolled trial. Gastroenterology 2009;137:1661-1668.e1-2.

-5 Hogan MC, Masyuk TV, Page LJ, Kubly VJ, Bergstralh EJ, Li X, Kim B, King BF, Glockner J, Holmes DR 3rd, Rossetti S, Harris PC, LaRusso NF, Torres VE: Randomized clinical trial of long-acting somatostatin for autosomal dominant polycystic kidney and liver disease. J Am Soc Nephrol 2010;21:1052-1061. 


\section{Case Reports in Nephrology and Dialysis}

\begin{tabular}{l|l}
\hline DOI: 10.1159/000477664 & $\begin{array}{l}\text { ( ) 2017 The Author(s). Published by S. Karger AG, Basel } \\
\text { www.karger.com/cnd }\end{array}$ \\
\hline
\end{tabular}

Mizuno et al.: Tolvaptan for the Treatment of Enlarged Polycystic Liver Disease

6 Qian Q, Du H, King BF, Kumar S, Dean PG, Cosio FG, Torres VE: Sirolimus reduces polycystic liver volume in ADPKD patients. J Am Soc Nephrol 2008;19:631-638.

-7 Iijima T, Suwabe T, Sumida K, Hayami N, Mise K, Hoshino J, Takaichi K, Ubara Y: Prediction of hepatic cyst recurrence after minocycline hydrochloride aspiration sclerotherapy using cyst computed tomography values. Hepatol Res 2017;47:419-424.

-8 Torres VE, Chapman AB, Devuyst 0, Gansevoort RT, Grantham JJ, Higashihara E, Perrone RD, Krasa HB, Ouyang J, Czerwiec FS; TEMPO 3:4 Trial Investigators: Tolvaptan in patients with autosomal dominant polycystic kidney disease. N Engl J Med 2012;367:2407-2418.

9 Mancinelli R, Franchitto A, Glaser S, Vetuschi A, Venter J, Sferra R, Pannarale L, Olivero F, Carpino G, Alpini G, Onori P, Gaudio E: Vasopressin regulates the growth of the biliary epithelium in polycystic liver disease. Lab Invest 2016;96:1147-1155.
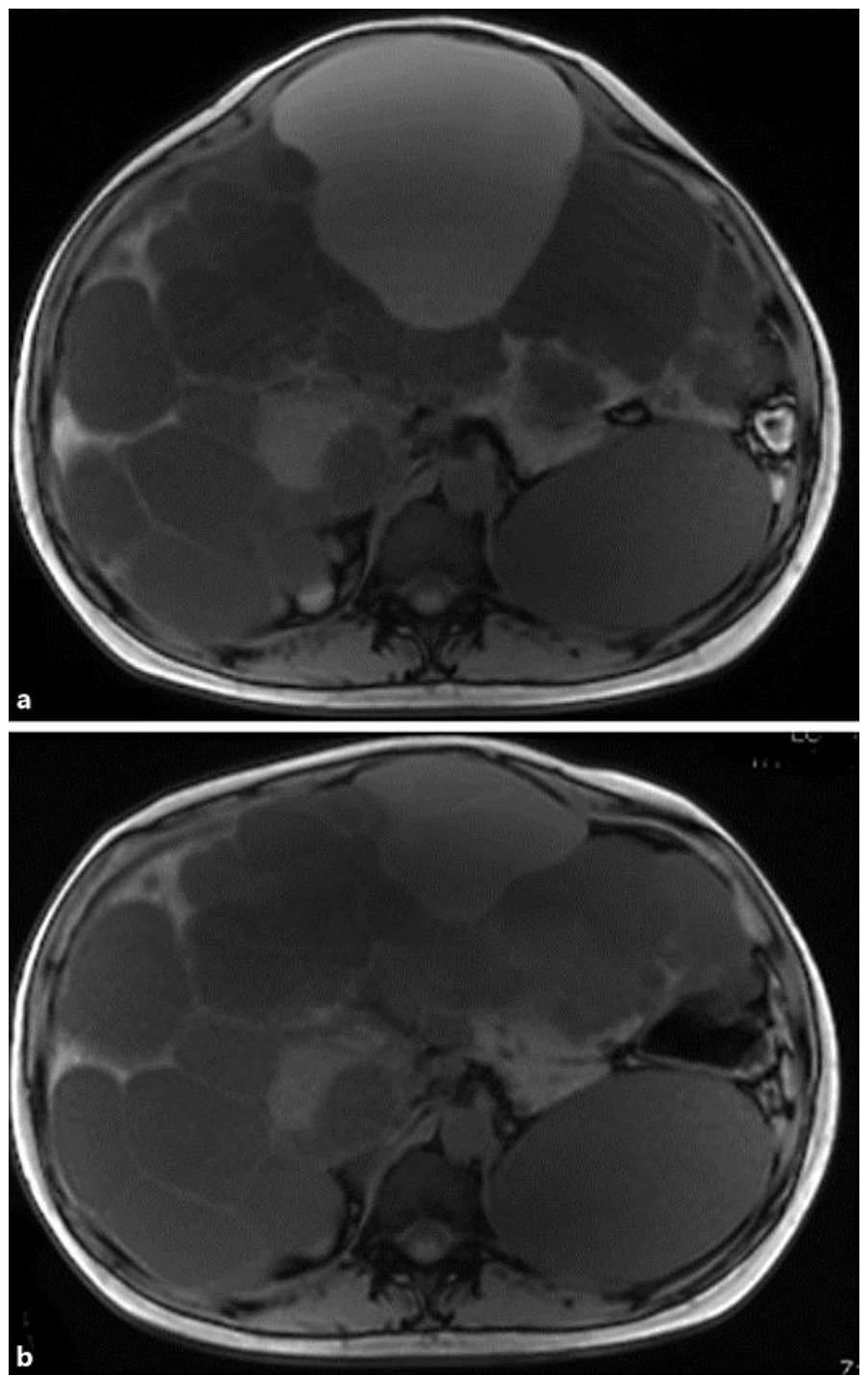

Fig. 1. a MRI before the administration of tolvaptan. b MRI after 17 months of tolvaptan therapy. 